\title{
Implementation of 2-Inch Grading Technique for Making Blouse Pattern in Modest Business
}

\section{Harsuyanti Lubis}

Vocational, Education Program, Fashion Design Studies Program Faculty of Engineering Jakarta State University

\section{Abstract}

This study aims to create a model to make patterns for modest customers in a faster way. The problem of this study is derived from the obstacles that are often experienced by modest entrepreneurs in making patterns for customers. The result of the study of implementing an individual pattern using grading system shows that there are several points that still need attention for further research. The instruments used are sheets of observation, with scales 3-1. These points are the position of the neck, waist, and shoulder lines. Meanwhile, the front length, appearance of the bust, hip, and dart side are already good. The output of this research is a model to make patterns for modest

Corresponding Author: Harsuyanti Lubis pikirinlubis@yahoo.com

Received: 11 January 2019 Accepted: 14 February 2019 Published: 25 March 2019

Publishing services provided by Knowledge E

(c) Harsuyanti Lubis. This article is distributed under the terms of the Creative Commons

Attribution License, which permits unrestricted use and redistribution provided that the original author and source are credited.

Selection and Peer-review under the responsibility of the 3rd ICTVET 2018 Conference Committee. business, by applying pattern grading technique principles, for women's blouses. The weakness of this study is that the pattern master is not built by standardized size because until now there has been no standard clothing size for Indonesian women.

Keywords: 2-inch grading technique, master pattern, grading technique adjustment result blouse, modest

\section{Introduction}

Clothing is a primary need of human that initially serves as a protector of climate and insect disturbance. Along with the development of the era, the function of wearing cloth also changes. Clothing is produced in two ways, namely individually and mass product. There are several steps to produce a clothing. Starting from the pattern, cutting the fabric and sewing it, so that it becomes a clothing. Patterns are obtained through construction and draping. Construction patterns are made based on a list of sizes, both individual and standard sizes. The finished and reader patterns are the example of patterns made according to standard size.

Modest is one of examples of a business in the field of clothing, which makes a variety of clothing models, which either fits the body shape, or is made loose depending on the order. In Modest, the pattern is made according to the size of the customer / order. 
size of human body is very diverse, but sometimes there are similarities on the size of some parts of the body.

Pattern grading design refers to the size of inches, while the construction pattern in Indonesia uses centimeter size. In industries that make mass clothing such as convection, one pattern is used to make several pattern sizes S, M, L, LL. For this reason, one pattern is needed to become the "master" to be graded, so that it becomes a number of patterns. The "master" pattern is shifted, referring to difference in size so that other size patterns are created. On the other hand, pattern grading is faster, but the clothing doesn't fit quite well on the body.

Thus, it is necessary to create a pattern making model in modest which can overcome the constraints in making patterns for customers. Based on the problems that have been raised, the research problem includes the implementation of pattern grading technique in making blouse pattern. How to use a pattern that is already available to become a blouse pattern according to the criteria of a good blouse by referring to pattern grading technique. The research problem is: How to make a blouse pattern model by implementing a 2 -inch grading technique, in modest business?

\section{Methods and Equipment}

\subsection{Methods}

This study employed research and development method. This method is used to produce certain product and examine the effectivity of the product. The study was initially started with analyzing the pattern grading blouse from a book source entitled "Coupe a Plat Les Transformations" and making the Meyneke pattern blouse with scale 1:4. The result of the analysis of these two patterns was developed into a model pattern which could be developed and used as the "master" to make several other patterns or duplicate patterns.

\subsubsection{Object of study}

The object of this study was a model blouse pattern which was made from a developed 2-inch pattern grading technique which used the body size of 5 models whose body height were between $158-165 \mathrm{~cm}$ and with $52-69 \mathrm{~kg}$ weight. There were 10 blouses made. 5 blouses were made with "master" patterns and the other five blouses were 
made with implementation patterns. The cloth used was blancu and the Japanese cotton. These two types of cloths were selected as their fabrics were dense and stable.

\subsubsection{Subject of study}

The subjects of the study were five panelists as informants who have backgrounds from apparel design study and are competent in assessing and giving information about blouses. The three of them are the assessors of sewing competence from Lembaga Sertifikasi Kompetensi (Certification and Credentialing Institute) of Apparel Design and the other two are lecturers in the Apparel Design Education Study Program.

\section{Results}

The blouse pattern which would be made was a model pattern of blouses without collar and sleeves. The blouse pattern used was a finished-blouse pattern from Meyneke pattern. On its front part, there are shoulder and waist darts. On its back part, there are also shoulder and waist darts. The initial blouse pattern design referred to pattern grading and blouse pattern made from Meyneke pattern. The pattern on the image was taken from grading book "Coupe a Plat Les Transformations". On the initial blouse pattern, it was seen that the lowest shoulder point fell at $2.5 \mathrm{~cm}$.

The result showed that there was swell on the shoulder/bust/neck part, or, on the other pattern, the shoulder was pulled back. On the back part, there was a part which was wrinkled, swelled, or pulled around the neck, shoulder, and waist. From the data obtained, the shoulder size of some women was ranging from 11 to $13 \mathrm{~cm}$.

The data showed that the shoulder lowest falling point of Meyneke pattern was ranging from 4.7 to $5.7 \mathrm{~cm}$. To revise the pattern, there was an additional size made which is the examined pattern on the five patterns with scale 1:4.

\section{Discussion}

A shoulder line influences on how a cloth drapes nicely on body. The location of the highest and lowest shoulder points must be precise so that the clothes can hang perfectly (smooth) without any parts that are pulled or swell.

A pattern would influence the final product of a dress. The results showed that a blouse for someone could be made from someone else's patterns. Therefore, with grading techniques, we could make another pattern from an existing pattern. Although 


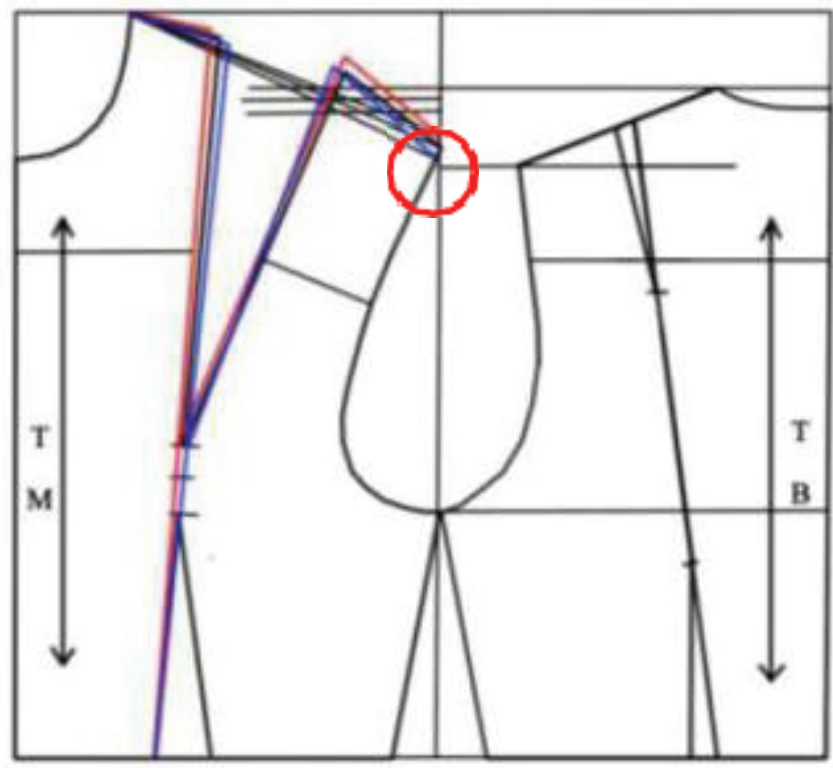

Figure 1: The Differences of Shoulder Point on Meyneke Patterns.

there are some parts of the pattern that does not give the best result in the implementation pattern, such as neckline position, waistline display, shoulder line, and highest shoulder point, which suits the master pattern better.
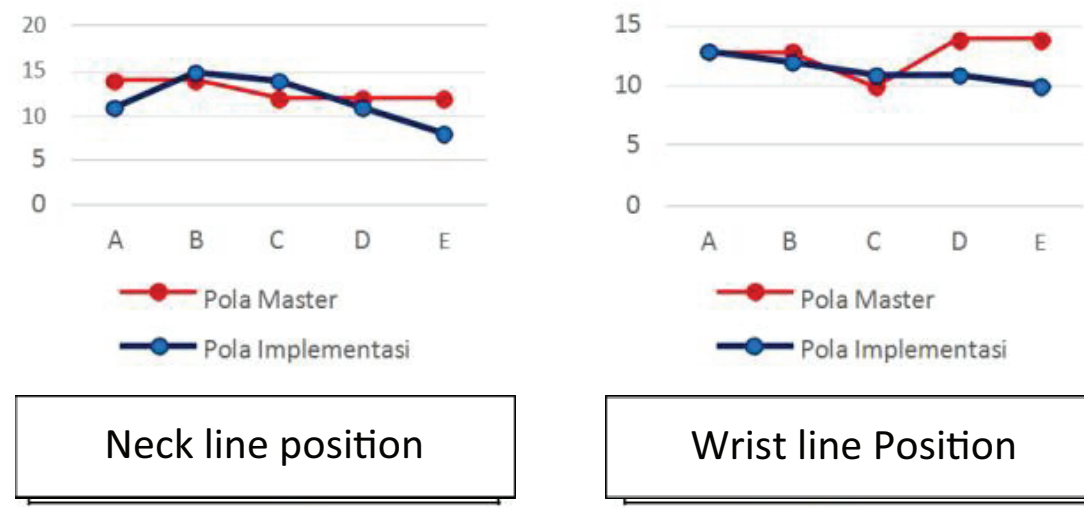

\section{Wrist line Position}
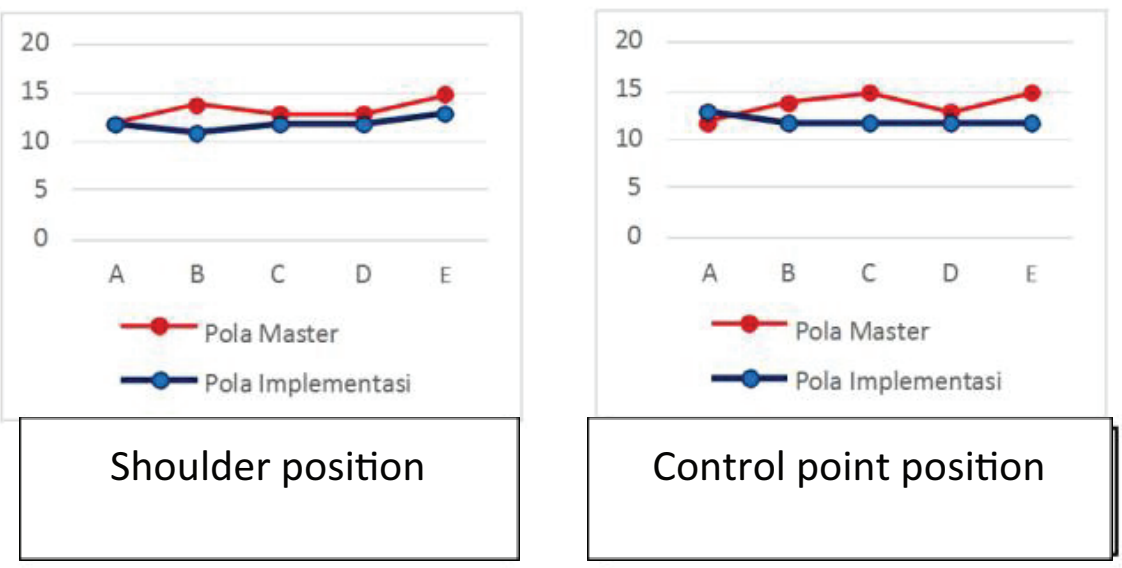
The graph above shows from 10 blouses, 5 blouses from the master pattern and 5 blouses from the implementation pattern, it seems that there is not much difference. This explains that making blouses by applying a grading pattern making system.

The implementation pattern works better in certain parts such as the front waist length lining position, appearance of the bust line, waist position, appearance of the pelvis, appearance of the sideline, the upper front dart position and the waist front dart position.

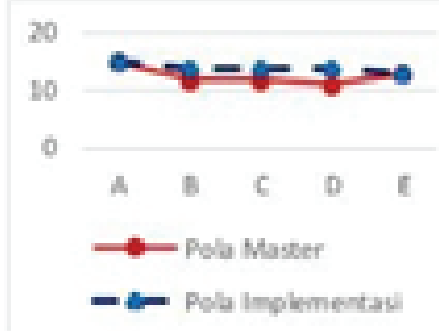

Gambar 31. Grafik Kedadukan Garis Panjang Miki

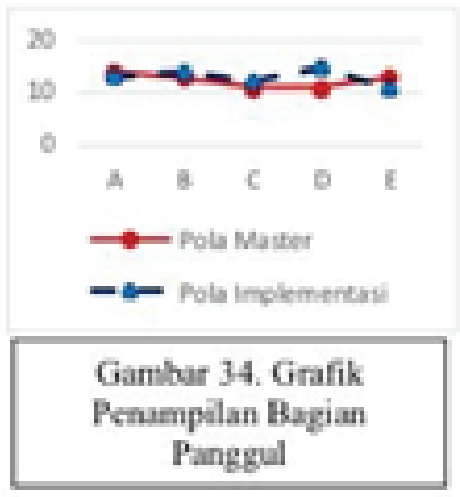

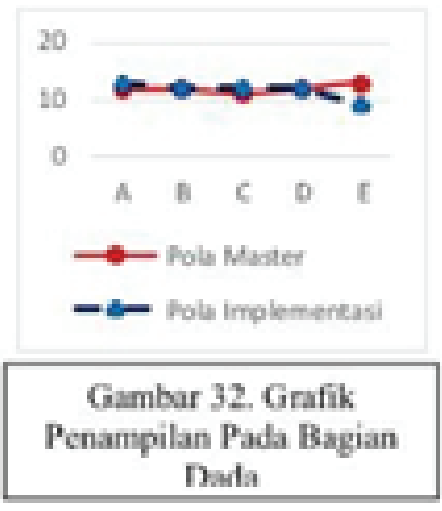

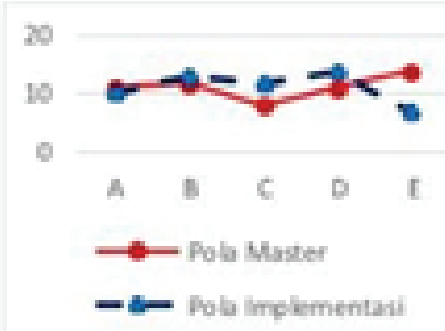

Gambar 33. Grafik

Kodudukn Garis Pinggang
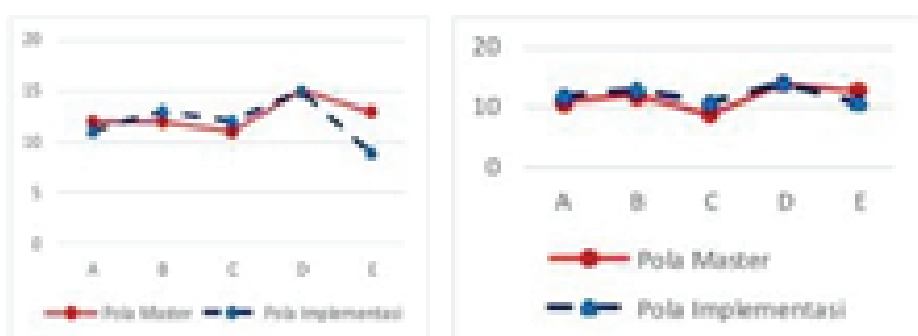

Gambar 35. Gratik Panapilin Gaxis Sisi

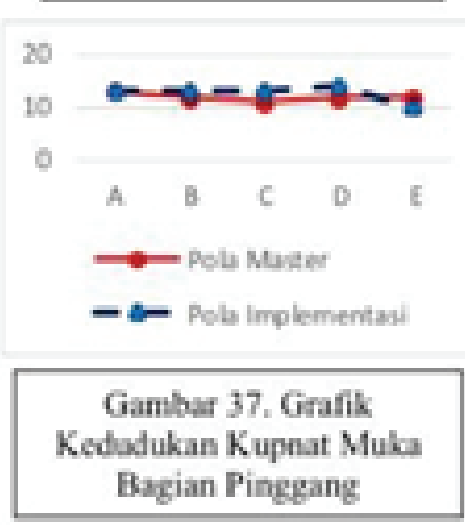

This is because the location of the shoulder point on the implementation pattern is not changed as the testing measurement is not calculated and the only changes made were on the circumference and width size, considering the five models' body height is relatively similar. But the overall results were sufficient. 
For implementation pattern results, it indicated that there was no difference in some indicators of the "master" and implementation pattern. Thus, this explains that implementing a 2 -inch grading technique on an existing pattern can be done, in order to get a new pattern, as long as the pattern size is known.

In the fashion making mechanism on modest, there were fitting stages I and II. In this stage, we improved any less fitting or draping parts. The results showed that there were not much value differences between blouses that were made using "master" patterns and implementation patterns. For that reason, the implementation of 2 -inch grading techniques in the procurement of patterns in the modest was possible to do.

\section{Conclusion}

To make construction patterns, it required calculations, formulations and procedural steps. The construction pattern is generally used in modest business.

In the mass industry, such as convection or garment factory, procurement patterns are carried out in Grading. The Grading method produces several different size patterns in a short amount of time. Implementation of grading techniques in individual patterns by increasing test measurement, it generated new patterns for other customers with fairly accurate results even though there should be improvement at some points. Hence the Grading theory did not have to be fixed as it could produce other patterns from one pattern alone.

\section{Funding}

This work was supported by the BLU DIPA UNJ.

\section{Acknowledgement}

The author would like to thank the dean of the Faculty of Engineering who facilitated this research, to the assessors the fashion competency test from LSK (Certification and Credentialing Institute) of Apparel Design, and to the students who helped during the implementation of this research. 


\section{References}

[1] Cooklin, Gerry. 1992. Pattern Grading For Men's Clothes. New Delhi: Blackwell Science.

[2] Gilewska, Teresa. 2008. Coupe A Plat Les Transformations. Paris: Groupe Eyrolles.

[3] Meadows, Toby. 2012. How To Set Up \& Run A Fashion Label. Hongkong: Laurance. King Publishing Ltd.

[4] Xiu, Y., Wan, Z.K., \& Cao, W., (2011). A Construction Approach Toward a Parametric Pattern-Making Model. SAGE, 980-990.

[5] Fang, Jing-Jing., \& Ding, Yu. (2008). Expert-Based Costumized Pattern-Making Automation: Part 1. Basic Patterns. Emerald Insight Group Publishing Limited. Vol. 20, No.1, 26-40.

[6] Sugiyono. 2011. Metode Penelitian Kuantitatif dan Kualitatif dan R\&D. Bandung: Alfabeta 